\title{
Trayectorias de afrodescendientes esclavizados durante la transición al trabajo libre en la ciudad de Paraná
}

\section{Trajectories of enslaved afrodescendants during the transition to free labor in Paraná City}

\section{Sosa, Francisco}

Francisco Sosa fsosa@unsam.edu.ar Laboratorio de Investigación en Ciencias Humanas - Universidad Nacional de San Martín - Consejo Nacional de Investigaciones Científicas y Técnicas (LICH-UNSAM-CONICET), Argentina

Estudios Sociales. Revista Universitaria Semestral Universidad Nacional del Litoral, Argentina

ISSN: 0327-4934

ISSN-e: 2250-6950

Periodicidad: Semestral

núm. 61, e0008, 2021

estudiossociales@unl.edu.ar

Recepción: 31 Julio 2020

Aprobación: 14 Agosto 2021

URL: http://portal.amelica.org/ameli/jatsRepo/293/2932743010/ index.html

DOI: https://doi.org/10.14409/es.2021.2.e0008

El contenido está bajo Licencia Creative Commons AtribuciónNoComercial-Compartir Igual 4.0 Internacional. Atribución - No Comercial - Compartir Igual (BY-NC-SA): no se permite un uso comercial de la obra original ni de las posibles obras derivadas, la distribución de las cuales se debe hacer con una licencia igual a la que regula la obra original.

\section{(i) (2)}

Esta obra está bajo una Licencia Creative Commons AtribuciónCompartirIgual 4.0 Internacional.
Resumen: Este trabajo indaga en el derrotero seguido por los afrodescendientes esclavizados de la ciudad de Paraná llegado el momento de la abolición definitiva de la esclavitud en 1853. Poniendo el foco en sus experiencias y trayectorias, se procura encontrar algunas pistas para comprender las transformaciones en las relaciones de trabajo y el rol de estos sujetos en la reconfiguración del mercado laboral a nivel local. El punto de partida es la Estadística de esclavos de la provincia de Entre Ríos realizada en 1848. Considerando la información que brinda sobre Paraná, se apela a la vinculación nominal con otros registros, tales como censos provinciales y nacionales, actas de bautismo, matrimonio y defunción, protocolos notariales, causas civiles y comerciales. A partir de estos documentos, se reconstruyen trayectorias laborales, redes familiares y formas de movilidad social, contribuyendo a iluminar el complejo e inacabado proceso de tránsito entre relaciones esclavistas y libres en un contexto situado.

Palabras clave: esclavitud, afrodescendientes, abolición, post abolición, mercado de trabajo.

Abstract: This article describes and analyzes the paths followed by the enslaved afrodescendants of the Paraná city at the transition to free labor. Focusing on their experiences and trajectories, it seeks to find some clues to understand the transformations in the labor relations and the role of these subjects in the reconfiguration of the labor market at the local level. The starting point is the Estadística de esclavos de la provincia de Entre Ríos redacted in 1848. Considering the information provides about Paraná, it proceeds to link with other sources, such as provincial and national censuses, church records, notary books and court cases. From these documents, it reconstructs labor trajectories, family networks and forms of social mobility, contributing to highlights the complex and unfinished transition process between slave and free labor in a situated context.

Keywords: slavery, afrodescendants, abolition, pos-abolition, labor market. 


\section{Introducción}

En la ciudad de Paraná ${ }^{[1]}$, capital de la provincia de Entre Ríos, los esclavos africanos y sus descendientes ocuparon un lugar central como mano de obra en las estancias, talleres y hogares de los vecinos más encumbrados de la sociedad a lo largo del siglo XIX. Sin embargo, en la historiografía tradicional de la provincia la temática de la esclavitud y la presencia misma de afrodescendientes ocupó un lugar marginal (Bosch, 1991; Martínez, 1910; Pérez Colman, 1946; Reula, 1971; Sors, 1981). Por un lado, al reproducir el tono de las fuentes, aquellos estudios afirmaron que se trató de un sistema escasamente desarrollado en la región y marcado por el trato benevolente de parte de los amos hacia sus esclavos. Por otro lado, atravesados por perspectivas teóricas esencialistas respecto a la cuestión racial, acotaron la presencia de los afrodescendientes al período en que la esclavitud estuvo vigente, certificando su paulatina desaparición luego de la abolición.

Con la renovación historiográfica y la adopción de perspectivas teóricometodológicas no esencialistas, en las últimas décadas aquellos postulados comenzaron a ser cuestionados (Masutti, 2000; Musich, 2019; Reina, 1973; Richard, 2019; Sosa, 2020). Estos estudios se ocuparon de colocar a los esclavos africanos y sus descendientes en un lugar de relevancia para pensar la historia de Paraná, concibiéndolos no sólo como un colectivo importante numéricamente, sino también como agentes activos en la configuración del entramado social, cuyo legado y presencia se extiende hasta nuestros días.

Este trabajo busca profundizar aquel cuestionamiento desde una óptica diferente y al mismo tiempo complementaria. Más allá de la importancia que la población esclavizada tuvo en términos cuantitativos, se pretende ahondar en las experiencias atravesadas por algunos de los sujetos que vivieron bajo esa condición durante el período de abolición de la esclavitud ${ }^{[2]}$ y configuración de un mercado de trabajo libre. En este sentido, la investigación se inscribe en un campo de estudios específico vinculado con la post abolición. Este se caracteriza por identificar y problematizar los modos de acceso a la ciudadanía e incorporación al mercado de trabajo tanto de la última generación de esclavos, como sus hijos y nietos, en los años inmediatamente posteriores a la abolición de la esclavitud. A diferencia de otros espacios de la región como Brasil, donde se ha suscitado una amplia producción al respecto ${ }^{[3]}$, en nuestro país dicho campo se encuentra en construcción ${ }^{[4]}$. Es con esos trabajos que esta investigación pretende establecer un diálogo.

A través de la reducción de la escala de observación, en este trabajo se busca reconstruir trayectorias laborales, redes familiares, estrategias de supervivencia y formas de movilidad social, sin perder de vista el modo en que sus acciones son condicionadas por el género y los procesos de racialización, en un contexto particular como es la ciudad de Paraná durante el siglo XIX. El punto de partida fue la Estadística de esclavos de la provincia de Entre Ríos. Realizado en 1848, este documento ofrece un panorama detallado de los sujetos que permanecían esclavizados hacia finales del período de gradual abolición. Considerando la información que brinda sobre la ciudad de Paraná, donde fueron consignados 53 esclavos, el desafío fue seguir algunas de sus trayectorias personales y familiares ${ }^{[5]}$. 
Para ello se apeló a la vinculación nominal con otros registros, tales como censos provinciales y nacionales ${ }^{[6]}$, actas de bautismo, matrimonio y defunción, protocolos notariales, causas civiles y comerciales.

Dos de esas historias organizan el texto. En primer lugar, indagamos en la vida de María, una mujer africana que fue esclava de un importante militar de la ciudad, reflexionando sobre los oficios de las mujeres en la ciudad, sus relaciones personales y laborales, así como las oportunidades abiertas para ella y su familia a partir de 1853. En segundo lugar, seguimos las huellas de Salvador, un joven brasilero que arribó a Paraná junto a su familia y la de su amo durante los últimos años de vigencia del sistema esclavista. Su caso permite un acercamiento único a los cambios acaecidos para los varones afrodescendientes con la abolición de la esclavitud, tanto en lo relativo a su inserción en un mercado de trabajo libre, como a la rearticulación de sus formas de sociabilidad. Tomando en consideración estas historias, por último, se ensayan algunas reflexiones respecto al modo en que habría operado el complejo e inacabado proceso de tránsito entre relaciones esclavistas y libres en la ciudad de Paraná, planteando una serie de interrogantes que en esta primera aproximación a la temática quedan sin respuesta.

\section{María Maruri: una vida al servicio de su amo}

Entre los esclavos registrados por Juan de Dios Ramos, comandante militar del departamento de Paraná se encuentra María Maruri ${ }^{[7]}$. Su apellido se explica por el de su amo, Don Pedro Maruri, vecino español reconocido de la ciudad por haber estado al mando del batallón cívico en la década de 1830 durante la gobernación de Pascual Echagüe, entre otros motivos (Martínez, 1910). Esta no habría sido, no obstante, su única ocupación. A través del censo de 1820 sabemos que también se había desempeñado como comerciante ${ }^{[8]}$. En aquella época era habitual que los hombres como Don Pedro participaran en diferentes áreas vinculadas a la vida política, económica y social de la ciudad.

De acuerdo con la información consignada en los censos y protocolos notariales, María había nacido en la última década del siglo XVIII y provenía de África. Más específicamente, algunos registros señalan su patria como Mina ${ }^{[9]}$. En términos geográficos, esta última se situaba en la costa occidental de África, y formaba parte de la zona cultural conocida como Baja Guinea (Thornton, 2004). No obstante, no podemos saber con certeza si dicha denominación refería a una unidad político-cultural africana preexistente o simplemente señalaba el puerto de embarque. Considerando estos aspectos, es posible suponer que María había sido capturada y transportada forzosamente desde el puerto de Mina hacia América durante la primera década del siglo XIX.

La documentación conservada en el Archivo Notarial ofrece algunos indicios para reconstruir el derrotero seguido por María hasta llegar a Paraná. En efecto, gracias a aquella sabemos que su primer destino fue el puerto de Bahía en Brasil. Desde allí fue trasladada en el bergantín Felicidad hacia el puerto de Buenos Aires, arribando al mismo en marzo de $1810^{[10]}$. Ese tipo de comercio se había facilitado tras las reformas borbónicas suscitadas a fines del siglo XVIII, cuando en pos de convertir a las colonias en espacios económicamente viables se habían aprobado una serie de medidas entre las que se encontraba la legalización del 
tráfico esclavista con Brasil (Borucki, 2017). Dicho comercio sólo retrocedería a partir de 1812 cuando fuera sancionada la ley de prohibición del tráfico atlántico de esclavos.

Dos meses después de arribar a Buenos Aires, María -a quien sólo se refiere como negrita bozal de nación Mina- fue vendida por Juan de Alagón, el propietario del barco $^{[11]}$, a Doña Josefa Ferrer por la cantidad de 230 pesos $^{[12]}$. A los pocos meses, esta última vendería a la referida esclava a Doña María Teresa Aguirre, vecina de la Villa de la Concepción del Uruguay en Entre Ríos, por 290 pesos $^{[13]}$. Junto a su nueva ama, María pasaría sus siguientes dos años, hasta que en 1812 fuera trasladada a La Bajada del Paraná para ser vendida a Doña Juana Monzón ${ }^{[14]}$.

No es posible conocer cuándo fue exactamente que María fue adquirida por Pedro Maruri, no obstante en el censo de 1820 encontramos una esclava de nombre María Rosa viviendo en la propiedad de aquél ${ }^{[15]}$. Volvemos a saber de ella al año siguiente, cuando contrae matrimonio con Alejandro González, negro libre proveniente de Guinea, según consta en el registro de la Parroquia Nuestra Señora del Rosario de la ciudad de Paraná ${ }^{[16]}$. En el mismo documento ella es consignada como negra, esclava de Don Pedro. Como se observa en el estudio realizado por Reina, la mayoría de los matrimonios del período en la ciudad de Paraná se caracterizaban por realizarse entre sujetos que eran comprendidos como pertenecientes a un mismo grupo étnico-racial, siendo escasos los casamientos mixtos (Reina, 1973). El vínculo contraído entre María y Alejandro no fue una excepción.

En 1822, María y Alejandro se hicieron presentes en la Parroquia Nuestra Señora del Rosario de Paraná para bautizar a su hijo, a quien pusieron de nombre Mateo ${ }^{[17]}$. Ese mismo año había sido sancionado el Estatuto Provisorio Constitucional para la provincia de Entre Ríos. En este se reconocían y ratificaban todas las disposiciones dadas por la Asamblea del Año XIII, prohibiendo el tráfico de esclavos en el territorio y sometiendo al régimen de libertos a todos los hijos de esclavas nacidos luego del 31 de enero de $1813^{[18]}$. De acuerdo con lo establecido por dicho estatuto, Mateo fue registrado como liberto y su bautismo fue gratuito. Como padrino figura Don Pedro Maruri.

Los padrinos tenían el deber serio y sancionado por la Iglesia de guiar el bienestar espiritual del niño y sustituir a sus padres en caso de enfermedad, muerte o ausencia (Graham, 2005). En este sentido, es posible pensar aquella elección como una estrategia orientada a garantizar la protección y cuidado de su propio hijo mediante el establecimiento de un lazo espiritual con un hombre de influencia política y mejor posición económica. Además, el padrinazgo abarcaba no solamente la relación entre padrinos y ahijados, sino también aquella existente entre los padrinos y los padres del niño, que se convertían en compadres. Así, reforzar el vínculo con su amo podría haber traído ciertos beneficios a María, aunque a costa de fortalecer también la relación paternalista con Pedro.

Esa relación de carácter asimétrico posiblemente haya estado acentuada por el hecho de residir en el mismo hogar que su amo, como queda registrado en el censo realizado en 1824. Allí, Don Pedro figura como el propietario, a continuación, aparecen su mujer Doña María Rosa Aguilar y su hija María Lorenza Maruri ${ }^{[19]}$. Más abajo es registrada María junto a Mateo. También aparece un niño de dos 
años de nombre Diego. Por registros posteriores sabemos que también era hijo del matrimonio, no obstante, no se pudo hallar el registro de su bautismo. El censo no ofrece ningún indicio sobre Alejandro.

El documento presenta cierta ambigüedad con relación a las categorías laborales y jurídicas, siendo las personas esclavizadas consignadas de este modo en la columna relativa a los oficios. En el caso particular de María, el censista decidió dejar aquella columna vacía, dando a entender que se trataba de una persona libre. A pesar de ello, tenemos algunos indicios sobre su ocupación gracias a otro apartado donde fue registrado el rol desempeñado por cada uno de los sujetos en el hogar. Allí, María fue anotada como criada ${ }^{[20]}$. Aunque este término técnicamente señalaba a una persona libre de cualquier origen, como indica Paulina Alberto al referirse al contexto abolicionista en Buenos Aires, en la práctica incluía a los servidores tanto libres como esclavizados y estaba estrechamente asociado con personas de origen africano o no blancas (Alberto, 2018).

Dicha referencia sugiere que María se desempeñaba en la casa de Don Pedro como trabajadora doméstica. Ello incluía una multiplicidad de actividades, tales como cocinar, cuidar de niños y ancianos, trabajar en las huertas, lavar, planchar y mantener la limpieza de la vivienda. Mateo y Diego también fueron consignados como criados. Efectivamente, el Reglamento rioplatense de 1813 no estipulaba una libertad inmediata para los hijos de las esclavas, sino que los sometía al régimen de patronato, por el cual se perpetuaba la condición de sujeción y trabajo no remunerado.

Ese mismo año, María y Alejandro volverían a concurrir a la mencionada parroquia para bautizar a Clemente ${ }^{[21]}$. No sería esta la última vez. En 1827 se presentarían para el bautismo de su hijo Julián ${ }^{[22]}$. Dos años más tarde para el de una niña a la que llamaron Lorenza Pastora ${ }^{[23]}$. El último de los registros de bautismo en que encontramos a María es del año 1834, en el que fue anotado un hijo legítimo del matrimonio al cual pusieron por nombre Gerónimo ${ }^{[24]}$. Siguiendo con lo establecido por la Asamblea del Año XIII y ratificado por el Estatuto Provincial, todos estos niños fueron consignados como libertos. En lo que respecta a los padrinos, se advierte una predilección por la familia del amo de María: Pedro es elegido padrino de Clemente y Julián, mientras que la hija de aquel, María Lorenza, aparece como madrina de Gerónimo.

Aquella inclinación a elegir padrinos en mejor posición económica y social no era una regla entre los sujetos esclavizados. Como se observa en los registros de bautismo de los hijos de otra de las esclavas consignadas en la estadística de 1848, ellos también elegían otros esclavos para establecer ese parentesco ritual. Se trata de María Deniz, esclava de Don Valentín Deniz, quien en seis de las ocho ocasiones en las que se presentó a bautizar a sus hijos, eligió a la esclava Petrona Larrosa como madrina ${ }^{[25]}$. Es posible pensar que, a la hora de decidir respecto a los padrinos, eran evaluados también aspectos tales como la confianza en la persona, la lealtad, el afecto y la amistad. El bienestar económico habría sido un factor de consideración, aunque no el único.

En 1839 María pierde a su compañero. El acta de defunción de Alejandro menciona que se trata de un moreno libre, proveniente de la Costa de África, y que falleció de muerte natural ${ }^{[26]}$. Las fuentes no permiten conocer su edad, 
oficio ni cómo este había adquirido su libertad. Quizás la hubiera alcanzado mediante su incorporación al ejército por medio de los rescates, un instrumento del que se sirvió el Estado para aumentar el reclutamiento de hombres en las armas (Candioti, 2016; Viola, 2019). Para los varones esclavizados durante el período revolucionario, este sistema se transformó en una posibilidad inédita de librarse del yugo de la esclavitud. Aunque se trata de una posibilidad concreta, no se encontraron documentos que vinculen a Alejandro con las milicias.

Más allá de su experiencia personal, el servicio militar fue una experiencia difícil de eludir para los afrodescendientes durante la primera mitad del siglo XIX. Ya sea como una obligación o una oportunidad de ascenso social, los pardos y morenos fueron una pieza esencial para mantener la maquinaria bélica en la provincia. Los hijos mayores de María no serían ajenos a esta realidad. A través del acta de matrimonio de Mateo González, efectuado en 1840, se advierte que éste se desempeñaba como soldado de artillería ${ }^{[27]}$. En lo que respecta a su hermano Diego, cuando contrajo matrimonio en 1847 , se lo registró como soldado de caballería de la provincia ${ }^{[28]}$.

En 1844 María declaró ante el censista que era africana, tenía 52 años ${ }^{[29]}$ y había quedado viuda ${ }^{[30]}$. Gracias a este documento sabemos que continuaba viviendo en la propiedad de Don Pedro ubicada en el Cuartel 1 de la ciudad. En la misma también habitaban su hijo Julián, de 14 años, Pastora de 12 años y Gerónimo de 8 años. Además, aparece una niña de 11 años de nombre Juliana. Aunque no se encontró su registro de bautismo, por documentos posteriores se confirma que ella también era hija de María y Alejandro ${ }^{[31]}$. La estadística provincial se completa con la mención de dos niños de nombre Juan y Pedro ${ }^{[32]}$. Aunque son descriptos de la misma forma que los hijos del matrimonio, las fuentes no permiten saber si aquellos también lo eran.

En lo que respecta al oficio de María, se la registró como sirvienta ${ }^{[33]}$. Su rol en el hogar de su amo continuaba relacionado con la reproducción cotidiana de los miembros de la familia. En la columna notas, se aclaró la condición de esclavitud en la que se encontraba. Al igual que sucediera veinte años atrás, sus hijos fueron consignados con la misma ocupación que María. De acuerdo con el Reglamento para libertos, ellos no podrían ejercer sus derechos completamente sino hasta los 16 años en el caso de las mujeres y 20 años los varones.

En 1848, el mismo año en que se ordenaba la realización de la estadística de esclavos, Don Pedro Maruri decidió otorgar la carta de libertad para después de sus días a María. De acuerdo con sus palabras, lo hacía en consideración a los servicios honrados y el buen comportamiento que ella había tenido a lo largo de todos esos años a su lado ${ }^{[34]}$. Como consta en dicho documento, se trataba de una manumisión condicionada a permanecer al lado de su amo por el resto de la vida de este, a lo cual se añadía la necesidad de brindar su servicio a María Lorenza, hija de aquel, por el término de un mes luego del fallecimiento de su padre ${ }^{[35]}$. Es probable que las palabras afectivas utilizadas por Don Pedro para referirse a María en su carta de libertad hayan sido sinceras. Después de todo ella había estado sirviendo en la casa de aquel por más de 30 años. No obstante, ello no debe hacer perder de vista que las manumisiones constituían un eficaz instrumento utilizado por los amos para asegurar la cooperación y docilidad de sus esclavos (Guzmán, 2018). En este sentido, las condiciones puestas por Don Pedro en ese mismo 
documento dejaban en claro que no iba a descuidar sus ambiciones personales por un mero acto de filantropía.

Un año después volvemos a tener noticias sobre la familia Maruri por medio de un nuevo censo levantado en la provincia. En la propiedad de Don Pedro, ya retirado de su cargo como teniente coronel, encontramos a María, quien declara tener 50 años y, como en 1844 , provenir de África y ser viuda ${ }^{[36]}$. Sus hijas Pastora y Juliana, de 18 y 19 años respectivamente, continúan viviendo en la casa. En lo que respecta a sus oficios, de modo similar a lo sucedido en los registros anteriores, las categorías jurídicas se confunden con las laborales. En aquella columna María es consignada como esclava y sus hijas, a pesar de haber alcanzado la mayoría de edad estipulada en el mencionado Reglamento, como libertas.

Esto último, que sugiere que a Juliana y Pastora no les había sido respetado el plazo legal de su patronato, pone en evidencia la precariedad estructural de la libertad a la que los hijos y, más aún, las hijas de las mujeres esclavizadas debían enfrentarse luego de la sanción de la ley de libertad de vientres ${ }^{[37]}$. Como señala Alberto, esto era particularmente cierto en la esfera del servicio doméstico, donde formas de esclavitud más o menos encubiertas podían persistir sin ningún control (Alberto, 2018). En efecto, la extensión ilegal del patronato fue solamente uno de los mecanismos a través de los cuales los amos y patronos buscaron disponer del trabajo y destino de los africanos esclavizados y sus descendientes. Como consecuencia de ello, los alcances de la libertad obtenida legalmente debió ser disputada por los propios afrodescendientes y confirmada en los tribunales, en las casas y en la calle, de modo casuístico y sobre la base de una intensa negociación y de luchas cotidianas (Candioti, 2019).

En 1849, un año después de que Don Pedro le extendiera su carta de libertad, María Maruri se convertiría en una persona libre. Sin embargo, no se dio como consecuencia del fallecimiento de su amo, sino por una orden del Excelentísimo Señor Gobernador Propietario de la provincia de Entre Ríos, Justo José de Urquiza $^{[38]}$. En efecto, en una carta enviada en agosto de aquel año por el coronel Don José Miguel Galán al administrador de rentas de la provincia, Don Casiano Calderón, se ordenaba a este último que entregara 150 pesos de la caja a su encargo al teniente coronel Don Pedro Maruri y extienda la carta de libertad de su morena esclava María Rosa ${ }^{[39]}$. Aunque en la provincia no se habían establecido leyes, decretos ni resoluciones que buscaran favorecer las manumisiones, no sería la única vez que por orden del gobernador se recurriría a la caja de la provincia para comprar la libertad de personas esclavizadas. Un hecho similar ocurrió ese mismo año, cuando Doña Catalina Troncoso de Culebrán vendió a Urquiza una mulata esclava llamada Gregoria, aclarándose que la compra se realizaba «con el loable y filantrópico objeto de darla libre de la esclavitud a que se halla[ba] sujeta» (Candioti, 2016).

Por medio de este acto particular, y a tan solo cuatro años de la abolición definitiva de la esclavitud, María Maruri obtenía su libertad. A partir de ello, es posible preguntarse ¿cómo se vería afectada la vida de María y la de sus hijos? ¿qué oportunidades y limitaciones traería consigo la libertad para una mujer que vivió la mayor parte de su vida esclavizada? La respuesta a estos interrogantes no es simple. No obstante, la indagación en el derrotero seguido por estas personas a partir de aquel año puede ofrecernos algunos indicios al respecto. 
En el censo nacional de 1869 hallamos viviendo en Paraná a una anciana María de 73 años ${ }^{[40]}$. Sobre su ocupación declaró ser costurera, un trabajo precario y pobremente retribuido, cuyas destrezas para su ejercicio probablemente las había adquirido durante sus años como esclava de la familia Maruri. Junto a ella se encontraba su hija Juliana y su nieto, quien al igual que su difunto esposo, se llamaba Alejandro ${ }^{[41]}$. Con relación al oficio, Juliana fue consignada como planchadora, mientras que su hijo de 12 años como sastre. A diferencia de su madre y su abuela, Alejandro había alcanzado cierta especialización para poder desempeñarse en una ocupación mejor paga y de mayor prestigio. Por otro lado, en contraste con María y Juliana, quienes declararon ser analfabetas, el joven afirmó saber leer y escribir.

No sabemos cuándo fue exactamente que María dejó de vivir con la familia de Don Pedro, no obstante, para el momento del censo, tanto ella como su hija contaban con una casa propia. El terreno en el que ésta se erigía había sido donado en 1857 por su hijo Julián. Hacía tiempo ya que este había dejado de vivir con su madre. En 1849 había contraído matrimonio con una mujer llamada Aniceta Góngora ${ }^{[42]}$. En el censo del mismo año, encontramos a esta pareja conviviendo en una propiedad perteneciente al comerciante Don José Salazar ${ }^{[43]}$. Con relación a su ocupación, declaraba ser latero. Es posible pensar que el aprendizaje de aquel oficio le proporcionara a Julián cierta estabilidad económica y, tras años de ahorro, pudiera adquirir un terreno para él y su familia.

En el documento respectivo a la donación realizada por Julián constaba además que, después de fallecida su madre, el terreno debía ser cedido gratuitamente a su hermana Juliana, con la condición precisa de que ella se hiciera cargo de los gastos para sepultarla y de una misa al enterrarla ${ }^{[44]}$. Aunque en 1855 Juliana había contraído matrimonio con Casiano Torres ${ }^{[45]}$, con quien había tenido además a sus hijos, en 1869 se encontraba viviendo con su madre. Ello podría haber estado relacionado con la precariedad económica en la que su familia se encontraba -en el expediente civil seguido por Juliana para solicitar el título del terreno declaraba encontrarse en estado de indigencia ${ }^{[46]}$ - o con la atención y cuidado que una mujer anciana como María requería. Quizás por ambas razones.

María Maruri moriría en 1870. Su partida de defunción indicaba que tenía 80 años y era viuda de Alejandro González ${ }^{[47]}$. No había referencias que delataran su pasado como mujer esclavizada ni su ascendencia africana. El registro aclaraba que se trataba de una persona pobre de solemnidad. Según el diccionario de la Real Academia Española de 1822, esa categoría se utilizaba para hacer referencia a quien «padece total necesidad y pobreza, por la que se ve obligado a pedir limosna para mantenerse ${ }^{[48]}$. En este sentido, el pobre de solemnidad no se distinguía del pobre a secas (Rebagliati, 2013). Esa etiqueta ponía en evidencia que, a pesar del cambio en su condición jurídica, la situación económica no había variado demasiado para María. Con una abolición que priorizó los intereses de los amos antes que los de las personas esclavizadas, las posibilidades de movilidad social se revelaron limitadas para una mujer que había dedicado la mayor parte de sus años económicamente activa a un trabajo no remunerado, relacionado con el cuidado y protección de una familia que no era la propia. 


\section{Salvador Antunes: la vida después de la esclavitud}

En la lista de esclavos que elevó a Don Miguel Galán el comandante militar de Paraná se encuentra también un joven de nombre Salvador. A su lado, en la columna relativa a los amos, aparece Doña Josefa Antunes, esposa del comerciante Don Ricardo Ferreira. Gracias a los documentos disponibles sabemos que Salvador era hijo de Manuel y Mariana, también esclavos pertenecientes a aquel matrimonio. Resulta difícil determinar su edad exacta, dado que las fuentes presentan datos disímiles. Si se observan las estadísticas provinciales, Salvador habría nacido entre 1836 y 1837 mientras que, si se apela a las nacionales, habría sido entre 1825 y 1828 . No obstante, si se pone en consideración la edad con la que es registrada su madre, se concluye que el joven esclavo debería haber nacido durante la década de 1830.

En lo que respecta a la procedencia, se advierte que Salvador era brasilero. De acuerdo con los documentos disponibles, es posible inferir que en la década de 1840 la familia de Ricardo y Josefa junto a sus esclavos había arribado a Paraná desde Brasil ${ }^{[49]}$, quizás con el objetivo de aprovechar las posibilidades de desarrollo comercial que la ciudad parecía ofrecer. Por aquellos años las fronteras entrerrianas habían comenzado a expandirse, aumentando el área disponible para la explotación de los recursos locales, mientras que la salida al río Paraná, donde confluían las rutas mercantiles que conectaban con los grandes centros productores y consumidores de la región, continuaba fomentando el crecimiento urbano. En ese contexto, habían surgido grandes oportunidades para las personas que estaban interesadas en los negocios y pequeñas empresas manufactureras. Como se advierte en los registros de la época, Don Ricardo parece haber sido una de ellas ${ }^{[50]}$.

El hecho de que Salvador haya nacido en el Imperio del Brasil y luego migrado hacia Paraná explica por qué, a pesar su corta edad, fuera registrado como esclavo en 1848. En efecto, la ley de libertad de vientres no alcanzaba a aquellos niños nacidos fuera del territorio de la Confederación. A su vez, aunque una ley complementaria al Estatuto Provisorio Constitucional de 1822 había establecido que todo esclavo que se presente en el territorio de la provincia proveniente de países extranjeros con el designio de ser vendido quedaría libre ${ }^{[51]}$, no existía ningún impedimento para que los inmigrantes simplemente arribaran a la provincia junto a sus esclavos.

Las fuentes con las que contamos impiden conocer la infancia de Salvador en Brasil, así como el derrotero seguido por él junto a sus amos hasta llegar a Paraná. El primer documento que hace referencia a la presencia de la familia en la ciudad es el censo provincial de 1844. Del mismo se deduce que no hacía mucho tiempo que habían migrado, dado que en la propiedad de Don Ricardo aparece un niño esclavizado de tan solo un año registrado como brasilero ${ }^{[52]}$. Salvador, al igual que su madre y los demás esclavos de la casa, fue consignado como sirviente ${ }^{[53]}$. Como se desarrolló anteriormente, el servicio doméstico era una de las principales ocupaciones en las que las personas esclavizadas eran empleadas, particularmente las mujeres y los niños.

Hacia 1849, como se advierte en el censo realizado aquel año, Salvador continuaba viviendo junto a su madre en la propiedad de Don Ricardo ${ }^{[54]}$. En lo 
que respecta a su oficio, el censista lo registró como esclavo. A diferencia de él, Mariana fue consignada como sirvienta, una muestra más de la ambigüedad antes señalada respecto a las categorías utilizadas para referir a la condición laboral y jurídica de los sujetos en los censos. A pesar de la imprecisión de esos términos, el registro diferenciado de la ocupación de Salvador con respecto a la de su madre - quien, por otro lado, también se encontraba esclavizada- permite pensar que el joven no era empleado exclusivamente en el servicio doméstico. Teniendo en cuenta el oficio de su amo, quien por aquellos años se había consolidado como un importante comerciante de la ciudad ${ }^{[55]}$, es posible considerar que aquel joven esclavizado estuviera vinculado a ese rubro, quizás como abastecedor de los almacenes y tiendas que por entonces proliferaban en la ciudad, o en la venta directa a los consumidores.

La Constitución Nacional sería sancionada en 1853 y con ella la abolición definitiva de la esclavitud. En su artículo 15 declaraba: «En la Confederación Argentina no hay esclavos: los pocos que hoy existen quedan libres desde la jura de esta Constitución; y una ley especial reglará las indemnizaciones a que dé lugar esta declaración». Lamentablemente no contamos con ningún documento que ofrezca indicios sobre el modo en que a partir de ese año se decidiera la libertad de Salvador y sus padres. Por registros posteriores, no obstante, sabemos que no transcurrió demasiado tiempo hasta que abandonaron la casa de sus antiguos amos. Durante la década de 1850, Mariana Antunes había recibido un terreno situado en los suburbios de la ciudad ${ }^{[56]}$. Este había sido donado por el Dean Miguel Vidal de la Iglesia Catedral. En aquel lugar la madre de Salvador había podido edificar un rancho, cercarlo y cultivar una huerta propia. Ese sería su hogar hasta sus últimos días.

Conocemos esta información gracias a un expediente civil iniciado por Salvador Antunes en 1868 para acreditar sus derechos al terreno luego de haber fallecido su madre. En el mismo declaró que el título de propiedad había sido extraviado, motivo por el cual presentaba testigos ${ }^{[57]}$. Entre estos se encontraba Don Felipe Antunes, quien expresó ser brasilero, de más de 50 años, vecino de la ciudad desde hacía como 20 años, soltero y de profesión techador ${ }^{[58]}$. Gracias a los censos provinciales sabemos que este hombre había sido también esclavo de Ricardo Ferreira. Desconocemos si existía algún tipo de parentesco con Salvador, no obstante, el hecho de que este último optara por aquel para testificar a su favor parece indicar que los vínculos construidos durante la experiencia como esclavos de la familia Ferreira Antunes habían perdurado en el tiempo.

Además de la sociabilidad tejida en torno a su ascendencia africana y experiencia como migrante esclavizado, Salvador apelaría a los lazos construidos en su lugar de trabajo. En efecto, otro de los testigos presentados fue Don José Méndez, quien declaró ser entrerriano de más de 50 años, casado y de profesión abastecedor $^{[59]}$. Como se desprende del censo nacional realizado en 1869 , Salvador también se desempeñaba en aquel oficio ${ }^{[60]}$. Quizás había aprendido del mismo en la época en que trabajara como esclavo para el comerciante Don Ricardo. Las fuentes disponibles no permiten saberlo con certeza.

Por otro lado, en dicho censo Salvador expresó tener 44 años, estar soltero y provenir de Brasil. Al igual que sucediera con María Maruri, no sabía leer ni escribir $^{[61]}$. Por registros posteriores conocemos que se encontraba viviendo en 
una casa de su propiedad que había recibido, al igual que su madre, durante la década de $1850^{[62]}$. En el mismo domicilio fue registrada una mujer llamada Dorotea Sandoval de 40 años, natural de la provincia de Entre Ríos ${ }^{[63]}$. Declaró estar soltera y trabajar como sirvienta. Tampoco sabía leer ni escribir. Dos años después ambos deberían afrontar la pérdida de una hija. Aunque no consta ningún registro de matrimonio entre ellos, y en todos los censos aparecen como solteros, en la partida de defunción de la niña, a la cual habían puesto por nombre María del Socorro, se la consideró como hija legítima ${ }^{[64]}$.

En 1875 Salvador Antunes vuelve a acudir al juzgado, esta vez para acreditar la posesión de la casa en la que se encontraba viviendo desde la época en que había obtenido su libertad ${ }^{[65]}$. No teniendo el título de propiedad procedió a presentar testigos. Al igual que en 1868 , Salvador eligió para testificar a una persona que conocía desde su infancia en la casa de la familia Ferreira Antunes. Se trataba de Don Joaquín Antunes, quién declaró tener 60 años, ser africano, estar casado y tener como profesión la de labrador ${ }^{[66]}$. Como se observa en la estadística de 1848, este hombre también había sido esclavo de Don Ricardo y Doña Josefa. $\mathrm{Al}$ momento de presentarse como testigo se encontraba viviendo en el terreno lindante al reclamado por Salvador. Lo había obtenido durante la década de 1850 del mismo modo que lo hiciera Mariana Antunes, y presumiblemente Salvador, a partir de una donación realizada por el Dean Miguel Vidal de la Iglesia Catedral ${ }^{[67]}$.

A pesar de su pasado como esclavizados y su visible ascendencia africana tanto Felipe como Joaquín fueron registrados como Don, título reservado hasta hacía pocos años a los vecinos respetados de la ciudad. Esta aparente igualación social que se daba en el discurso jurídico, no obstante, no se condecía con las representaciones construidas sobre estos sujetos por parte de la élite político-administrativa encargada de conducir el destino de la incipiente Nación argentina. En efecto, aquella había diagnosticado que la raíz del atraso en el que el país se encontraba estaba relacionada con la inferioridad de los componentes raciales de la sociedad. Abrevando en estas ideas, desde la década de 1850 el gobierno de Justo José de Urquiza estaba promoviendo la formación de colonias agrícolas y la introducción de inmigrantes europeos que renovaran la raza, entendiendo que esta transformación vencería por sí misma la barbarie (Suárez y Tornay, 2011). La igualdad jurídica difundida por la Constitución de 1853 convivía entonces con una jerarquía racial más o menos oculta que postulaba la superioridad de los sujetos blancos y europeos por sobre los mestizos, negros, mulatos e indios.

Aquella igualación social en términos jurídicos tampoco guardaba correlación con las oportunidades reales de movilidad social ofrecida a los afrodescendientes que habían atravesado por la experiencia de la esclavitud y sus familiares. Por esos años, la expansión capitalista había comenzado a modificar el mercado laboral en la ciudad y quienes tenían las habilidades más requeridas por este eran los inmigrantes europeos que estaban arribando de forma masiva. A pesar de haber adquirido diferentes destrezas a lo largo de sus años como trabajadores, debido a su falta de especialización y el hecho de ser analfabetos, eran escasas las posibilidades de que personas como Salvador, Felipe y Joaquín consiguieran 
trabajos que no fueran solamente temporarios, pobremente retribuidos y realizados en condiciones precarias.

Hacia 1895, año en que se realizó el Segundo Censo Nacional, Salvador continuaba viviendo en la ciudad. En esta ocasión, declaró al censista tener 67 años, estar soltero y provenir de Brasil ${ }^{[68]}$. En cuanto a su oficio fue consignado como jornalero. Además, se registró su condición de propietario y se aclaró que no sabía leer ni escribir. Continuaba viviendo junto a Dorotea Sandoval, de 60 años, también soltera y de oficio lavandera ${ }^{[69]}$. Este es el último registro en el cual encontramos a Salvador y su familia. Felipe había fallecido en 1876 en estado de pobreza. Su testamentaria ponía en evidencia que el techo de la casa en la que vivía estaba completamente desecho y los pocos bienes que poseía se encontraban en muy malas condiciones ${ }^{[70]}$. Las fuentes disponibles no permiten conocer el derrotero seguido por Joaquín.

\section{Reflexiones finales}

A lo largo de este trabajo nos adentramos en la historia de la esclavitud, su abolición, y la configuración de un mercado de trabajo libre, en una ciudad del interior argentino. Para ello nos enfocamos en un conjunto de historias particulares, de personas que atravesaron por la experiencia de la esclavitud durante las últimas décadas en que ese sistema estuvo vigente, y vivieron como libres en el mundo posabolicionista. Sus trayectorias nos mostraron que la transformación de los marcos legales trajo consigo la obtención de una mayor autonomía, aunque ello se tradujera simplemente en la posibilidad de elegir entre nuevas relaciones de dependencia.

Tanto el oficio declarado por María como los de Salvador, Felipe y Joaquín en los censos nacionales ponen en evidencia que habían abandonado las relaciones laborales con sus antiguos amos y habían conseguido ingresar al mercado como trabajadores asalariados. Sin embargo, las habilidades que habían adquirido durante sus trayectorias como esclavizados no eran las más aptas para progresar en el sistema económico que se estaba configurando. Como se advierte en esos documentos, las actividades que pasaron a efectuar poco se diferenciaban de las que habían realizado durante sus años como esclavos. Todas ellas compartían el hecho de ser precarias, temporales y mal pagas.

A pesar de las características comunes, las trayectorias laborales revelan opciones diferentes si consideramos el derrotero seguido por María y sus hijas en comparación con las que supieron aprovechar sus hijos varones. Como esclava de Don Pedro, María había dedicado la mayor parte de su vida a las tareas de reproducción del hogar de su amo. Sus hijas, sometidas al régimen de patronato, debieron también servir en la familia de Don Pedro. En contraste, la carrera militar les había permitido a Diego y Mateo ganar no sólo autonomía frente a su patrón, sino también prestigio social. Julián, por su parte, con su oficio de latero, al parecer, había conseguido ahorrar lo suficiente como para comprar un terreno y dividirlo entre su familia. Para Juliana las oportunidades habrían estado más restringidas, debiéndose contentar con vivir junto a su madre, probablemente repartiendo el tiempo entre su trabajo como planchadora y el cuidado de aquella. 
Desde el punto de vista de la elite liberal afincada en los cargos de gobierno, la imposibilidad de adaptación a las nuevas exigencias del mercado por parte de personas como María y Salvador se relacionaba con su raza. Que les fuera mal a los sujetos imaginados como negros, mulatos, mestizos e indios, parecía confirmar su inferioridad e incompatibilidad con el mundo civilizado. Las teorías evolucionistas de carácter racista, reinterpretadas por políticos e intelectuales argentinos como Domingo Faustino Sarmiento y Juan Bautista Alberdi otorgaron un carácter científico a aquellos postulados. A partir de ese diagnóstico, las políticas en materia demográfica y laboral encontraron en el estímulo a la inmigración europea la respuesta a la creciente necesidad de mano de obra, cerrando las posibilidades a que la población nativa no especializada pudiera acceder a los beneficios del mercado capitalista en expansión.

En ese mundo marcado por una creciente desigualdad racializada, tanto para María y sus hijos, como para Salvador y sus compañeros de trabajo, los márgenes de acción eran limitados, y las posibilidades de ascenso social, escasas. Aquello no fue un impedimento para que estos acudieran a los juzgados a reclamar lo que consideraban que les pertenecía. A pesar de ser analfabetos y que, en consecuencia, otras personas escribieran y firmaran por ellos, gracias a las huellas que imprimieron en esos documentos es que podemos conocer algunas de las experiencias y desafíos por los que transitaron viviendo como personas libres en la ciudad. En ellos se delinea la importancia de los lazos construidos en torno a sus familias, su pasado como esclavizados, y su condición de sujetos socialmente negros, en sus intentos por progresar económicamente, o al menos, vivir con dignidad.

Resta mucho por conocer sobre la vida de estas personas y familias que atravesaron por la experiencia de la esclavitud y llegaron a vivir en un mundo posabolicionista. Es preciso continuar indagando en sus condiciones de vivienda y de trabajo, la forma en que rearticularon antiguas y construyeron nuevas formas de sociabilidad, así como el modo en que recrearon sus prácticas culturales. Esta es una primera aproximación, por lo que los interrogantes son más que las certezas.

\section{Referencias}

ABREU, MARTHA; MATTOS, HEBE (1998): Etnia e Identidades: Resistências, Abolição e Cidadania, Tempo, 3, Vol. 6, pp. 1-5.

ABREU, MARTHA; PEREIRA, MATHEUS (2011): Caminhos da liberdade: histórias da abolição e do pós-abolição no Brasil, Niterói, Universidade Federal Fluminense.

ABREU, MARTHA; DANTAS, CAROLINA; MATTOS, HEBE; LONER, BEATRIZ; MONSMA, KARL (2013): Histórias do pos-abolição no mundo atlântico. Volume 1: Identidades e projetos politicos, Niterói, Universidade Federal Fluminense.

ALBERTO, PAULINA (2018): «Liberta by Trade: Negotiating the Terms of Unfree Labor in Gradual Abolition Buenos Aires», en Journal of Social History, 0, Vol. 0, pp. 1-33.

ANDREWS, GEORGE (1989): Los afroargentinos de Buenos Aires. Buenos Aires, Ediciones La Flor. 
BORUCKI, ALEX (2017): De compañeros de barco a camaradas de armas. Identidades negras en el Rio de la Plata 1760-1860, Buenos Aires, Prometeo.

BOSCH, BEATRIZ (1991): Historia de Entre Rios 3, Buenos Aires, Editorial Plus Ultra.

CANDIOTI, MAGDALENA (2016): «Hacia una historia de la esclavitud y la abolición en la ciudad de Santa Fe, 1810-1853», en GUZMÁN, FLORENCIA; GELER, LEA; FRIGERIO, ALEJANDRO (comps.), Cartografias afrolatinoamericanas. Perspectivas situadas desde la Argentina. Buenos Aires, Biblos, pp. 99-122.

CANDIOTI, MAGDALENA (2019): «El tiempo de los libertos: conflictos y litigación en torno a la ley de vientre libre en el Río de la Plata (1813-1860)», en História (São Paulo), 38, 1-28.

CARRIZO, MARCOS (2011): Córdoba morena (1830-1880), Córdoba: Colección Rojo y Negro.

CASSANO, GUIDO (2020): «De soldados libertos a jornaleros y peones: africanos y afrodescendientes en Carmen de Patagones, 1820-1870», en GUZMÁN, FLORENCIA; GHIDOLI, MARÍA DE LOURDES (comps.), El asedio a la libertad: abolición y posabolición de la esclavitud en el Cono Sur, Buenos Aires, Biblos, pp. 375-406.

CHALHOUB, SIDNEY (1990): Visões da Liberdade. Uma história das últimas décadas da escravidão na corte, São Paulo, Companhia das Letras.

CHALHOUB, SIDNEY (2011): «The precariousness of freedom in a slave society (Brazil in the nineteenth century)», en International Review of Social History, 56, 405-439.

GELER, LEA (2010): Andares negros, caminos blancos. Afroporteño, Estado y Nación Argentina a fines del siglo XIX. Rosario, Prohistoria.

GRAHAM, SANDRA (2005): Caetana diz não. Histórias de mulheres da sociedade escravista brasileira, São Paulo, Companhia das Letras.

GUIMARÃES, ELIONE (2005): «Tensões remanescentes das senzalas: análise de tutorias de menores afrodescendentes (Juiz de Fora - MG, final do século XIX e início do XX)», en Revista Justiça y História, 5, vol. 9, pp. 1-29.

GUZMÁN, FLORENCIA (2018): «iMadres negras tenían que ser! Maternidad, emancipación y trabajo en tiempos de cambios y transformaciones (Buenos Aires, 1800-1830)», en Tempo, 24, vol. 3, pp. 450-473.

MACHADO, MARÍA HELENA; CASTILHO, CELSO (2015). Tornando-se livre. Agentes históricos e lutas sociais no processo de abolição, São Paulo, EDUSP.

MARTíneZ, BENIGNO (1910): Historia de la Provincia de Entre Ríos. Tomo Segundo, Buenos Aires, Talleres Gráficos de L. J. Rosso y Cía.

MASUTTI, MABEL (2000): La negritud en la Cultura Argentina, Paraná, Universidad Nacional de Entre Ríos.

MUSICH, WALTER (2019): «La situación jurídica del negro esclavo en tiempos pos-revolucionarios», en VIII Congreso Regional de Historia e Historiografia, Universidad Nacional del Litoral, 30 de mayo - 1 de junio.

PÉREZ COLMAN, CÉSAR (1946): Paraná 1810-1860. Los primeros cincuenta años de la vida nacional, Rosario, Talleres Gráficos Emilio Fenner S.R.L.

REBAGLIATI, LUCAS (2013): «Los pobres ante la justicia: discursos, prácticas y estrategias de subsistencia en Buenos Aires (1785-1821)», en Boletin del Instituto de Historia Argentina y Americana Dr. Emilio Ravignani, 38, pp. 11-42. 
REINA, RUBÉN (1973): Paraná. Social Boundaries in an Argentine City, Austin, University of Texas.

REULA, FILIBERTO (1971): Historia de Entre Ríos. Tomo 1, Santa Fe, Editorial Castellví.

RICHARD, ALEJANDRO (2019). «La población indígena y afrodescendiente de Paraná. Categorías socioétnicas entre 1755-1824», en Memoria Americana. Cuadernos de Etnohistoria, 27, pp. 169-187.

RIOS, ANA; MATTOS, HEBE (2004): «O pós-abolição como problema histórico: balanços e perspectivas», en Topoi, 5, vol. 8, pp. 170-198.

SORS, OFELIA (1981): Paraná: dos siglos y cuarto de su evolución urbana. 1730-1955, Paraná, Editorial Colmegna.

SOSA, FRANCISCO (2020): «La Estadística de Esclavos de 1848 como fuente para el estudio de la historia de la esclavitud y la abolición en Entre Ríos», en Revista Electrónica de Fuentes y Archivos, 11, vol. 11, pp. 108-131.

SUÁREZ, TERESA; TORNAY, MARÍA LAURA (2011): «Cautividad y servidumbre en tiempos de modernización. La conquista del Chaco austral y la mano de obra indígena en Santa Fe, décadas 1870 y $80 »$, en $I V$ Congreso de Historia e Historiografía. Facultad de Humanidades y Ciencias, Universidad Nacional del Litoral, 12 y 13 de mayo.

THORNTON, JOHN (2004): A África e os Africanos na formação do mundo atlântico. 1400-1800, Rio de Janeiro, Elsevier.

VALENZUELA, FÁTIMA (2020): «Recorridos abolicionistas entre 1830 y 1860 en la jurisdicción de Corrientes: consecuencias sociojurídicas del final de la esclavitud en pespectiva local», en GUZMÁN, FLORENCIA; GHIDOLI, MARÍA DE LOURDES (comps.), El asedio a la libertad: abolición y posabolición de la esclavitud en el Cono Sur, Buenos Aires, Biblos, pp. 343-374.

VIOLA, ARIEL (2019): «Las compañías de pardos y morenos en la Santa Fe revolucionaria», en VIJornadas del grupo de estudios afrolatinoamericanos, Centro Cultural de la Cooperación Floreal Gorini, 2 al 4 de septiembre.

\section{Notas}

[1] Los orígenes de la ciudad de Paraná se remontan al siglo XVII, cuando colonos santafesinos migraron hacia la costa este del río homónimo, instalándose en el sitio por entonces conocido como La Bajada. Aunque no cuenta con fecha de fundación, a partir de la erección de la capilla bajo la advocación de Nuestra Señora del Rosario y la institución de la Alcaldía de la Hermandad durante la década de 1730, la otra banda del Paraná se consolidó como centro poblado.

[2] En la región rioplatense, dicho período comienza con la Ley de Prohibición del Tráfico de Esclavos sancionada en 1812, continúa con la de vientre libre en 1813, y se extiende hasta la abolición definitiva, contemplada en la Constitución Nacional de 1853.

[3] La conformación de este campo de estudios particular-que vino de la mano de la renovación historiográfica acontecida en Brasil desde fines de la década de 1980- se centró, por un lado, en los cambios históricos que resultarían en el fin de la esclavitud y sus principales consecuencias (Chalhoub, 1990; Abreu y Mattos, 1998; Machado y Castilho, 2015; Rios y Mattos, 2004) y, por el otro, en la dinámica de construcción de identidades, los límites a los que los afrodescendientes se enfrentaron y las posibilidades con las que contaron luego de la abolición (Abreu, Dantas, Mattos, Loner y Monsama, 2013; Abreu y Pereira, 2011; Guimarães, 2005).

[4] En lo relativo a la historiografía argentina, la obra de George Reid Andrews sobre los afroargentinos de Buenos Aires (Andrews, 1989) representa un punto de quiebre. Centrados en la provincia de Buenos Aires, se destacan también la investigación de Lea Geler sobre la prensa 
afroporteña (Geler, 2010), así como la de Guido Cassano sobre los soldados libertos devenidos en jornaleros y peones de Carmen de Patagones (Cassano, 2020). En lo que respecta a otros espacios del país, contamos con los trabajos realizadas por Marcos Carrizo sobre Córdoba (Carrizo, 2011) y Fátima Valenzuela sobre Corrientes (Valenzuela, 2020).

[5] La estadística fue confeccionada a partir de la información brindada por los comandantes militares de cada uno de los departamentos en cumplimiento de una disposición realizada por Miguel Galán, por entonces ministro general de la provincia. En lo que respecta a Paraná y sus distritos, el comandante encargado fue Juan de Dios Ramos. Actualmente, los documentos se encuentran ordenados bajo el rótulo de Estadística de esclavos en el legajo 12, caja 2, serie VII, del Fondo de Gobierno del Archivo General de la provincia de Entre Ríos (AGPER). Dicho legajo, a su vez, se subdivide en la sección A, donde se conservan las listas de los comandantes militares, y la sección $\mathrm{B}$, la cual contiene la estadística en cuestión.

[6] Agradezco a Magdalena Candioti y Alejandro Richard por haberme facilitado las transcripciones realizadas de los padrones provinciales de 1820 y 1824 respectivamente. En lo que respecta a los censos de 1849 y 1869 , fueron consultadas las transcripciones realizadas por Liliana Cuenca y Amilcar Carrá, las cuales se encuentran publicadas en http://www.genealogia entrerios.com/censos-y-padrones.html.

[7] Su apellido varía de acuerdo con cada una de las fuentes, hallándose registrada como Marury, Maruli, Marulli, Maruni, Marune, Marules o Maxury. A los fines de este trabajo optamos por la referencia utilizada en la estadística de esclavos de 1848.

[8] AGPER. Censo de 1820. Copia digital (fuera de inventario).

[9] AGPER. Fondo de Gobierno. Serie VII Estadísticas y Censos 1823-1894. Caja 1. Legajo 2: Censo de habitantes. Paraná, 1824. Archivo Notarial de la provincia de Entre Ríos (en adelante ANPER). Libro del escribano Manuel Calderón 1847-1849. Folio sin numeración.

[10] ANPER. Libro del escribano Manuel Calderón 1847-1849. Folio sin numeración.

[11] Consultado en: www.slavesvoyages.org

[12] ANPER. Libro del escribano Manuel Calderón 1847-1849. Folio sin numeración.

[13] ANPER. Libro del escribano Manuel Calderón 1847-1849. Folio sin numeración.

[14] ANPER. Libro del escribano Manuel Calderón 1847-1849. Folio sin numeración.

[15] AGPER. Censo de 1820. Copia digital (fuera de inventario).

[16] Family Search. Registro de Matrimonios de la Parroquia Nuestra Señora del Rosario. Paraná 1800-1826. Imagen 127.

[17] Family Search. Registro de Bautismos de la Parroquia Nuestra Señora del Rosario. Paraná 1808-1830. Imagen 433.

[18] AGPER. Recopilación de leyes, decretos y acuerdos de Entre Ríos, Tomo I (1821-1824). Copia digital.

[19] AGPER. Fondo de Gobierno. Serie VII, Estadísticas y Censos 1823-1894. Caja 1. Legajo 2: Censo de habitantes. Paraná, 1824.

[20] AGPER. Fondo de Gobierno. Serie VII, Estadísticas y Censos 1823-1894. Caja 1. Legajo 2: Censo de habitantes. Paraná, 1824.

[21] Family Search. Registro de Bautismos de la Parroquia Nuestra Señora del Rosario. Paraná 1808-1830. Imagen 509.

[22] Family Search. Registro de Bautismos de la Parroquia Nuestra Señora del Rosario. Paraná 1808-1830. Imagen 589. 
[23] Family Search. Registro de Bautismos de la Parroquia Nuestra Señora del Rosario. Paraná 1808-1830. Imagen 702.

[24] Family Search. Registro de Bautismos de la Parroquia Nuestra Señora del Rosario. Paraná 1830-1845. Imagen 250.

[25] Family Search. Registro de Bautismos de la Parroquia Nuestra Señora del Rosario. Paraná, 1830-1845. Imágenes 110, 249, 429, 574, 611 y 650.

[26] Family Search. Registro de Defunciones de la Parroquia Nuestra Señora del Rosario. Paraná, 1832-1859. Imagen 162.

[27] Family Search. Registro de Matrimonios de la Parroquia Nuestra Señora del Rosario. Paraná. 1829-1860. Imagen 253.

[28] Family Search. Registro de Matrimonios de la Parroquia Nuestra Señora del Rosario. Paraná. 1829-1860. Imagen 331.

[29] Si consideramos el resto de los registros que dan cuenta de su edad, es más probable que haya sido más joven.

[30] AGPER. Fondo de Gobierno. Serie VII Estadísticas y Censos 1823-1894. Caja 1. Legajo 9: Censo de habitantes. Paraná, 1844.

[31] De hecho, se halló una partida correspondiente a 1832 que menciona al matrimonio bautizando una niña con el nombre de Juana. Dado que la fecha coincide con la edad declarada por Juliana en 1844, y que no se volvió a encontrar ninguna mujer con aquel nombre en registros posteriores asociados con la familia, es posible inferir que se trata de la misma persona. Registro de Bautismos de la Parroquia Nuestra Señora del Rosario. Paraná 1830-1845. Imagen 90.

[32] AGPER. Fondo de Gobierno. Serie VII Estadísticas y Censos 1823-1894. Caja 1. Legajo 9: Censo de habitantes. Paraná, 1844.

[33] AGPER. Fondo de Gobierno. Serie VII Estadísticas y Censos 1823-1894. Caja 1. Legajo 9: Censo de habitantes. Paraná, 1844.

[34] ANPER. Libro del escribano Manuel Calderón 1847-1849. Folio sin numeración.

[35] ANPER. Libro del escribano Manuel Calderón 1847-1849. Folio sin numeración.

[36] AGPER. Fondo de Gobierno. Serie VII Estadísticas y Censos 1823-1894. Caja 3. Legajo 1: Censo de habitantes. Paraná, 1849.

[37] Este concepto, utilizado por Chalhoub para pensar el abolicionismo brasilero, pone el foco en aquellas situaciones en que la línea entre esclavitud y libertad se vuelve borrosa, volviendo insegura la condición de los afrodescendientes libres y libertos (Chalhoub, 2011).

[38] AN. Libro del escribano Manuel Calderón 1847-1849. Folio sin numeración.

[39] AN. Libro del escribano Manuel Calderón 1847-1849. Folio sin numeración.

[40] Archivo General de la Nación (en adelante AGN). Primer Censo Nacional (1869). Copia digital. Tomo 18. Imagen 53.

[41] AGN. Primer Censo Nacional (1869). Copia digital. Tomo 18. Imagen 53.

[42] Family Search. Registro de Matrimonios de la Parroquia Nuestra Señora del Rosario. Paraná. 1826-1860. Imagen 400.

[43] AGPER. Fondo de Gobierno. Serie VII Estadísticas y Censos 1823-1894. Caja 3. Legajo 1: Censo de habitantes. Paraná, 1849.

[44] AGPER. Expedientes judiciales (fuera de inventario). Expediente seguido por Juliana Maruri (1874). 
[45] Family Search. Registro de Matrimonios de la Parroquia Nuestra Señora del Rosario. Paraná. 1826-1860. Imagen 550.

[46] AGPER. Expedientes judiciales (fuera de inventario). Expediente seguido por Juliana Maruri (1874).

[47] Family Search. Registro de Defunciones de la Parroquia Nuestra Señora del Rosario. Paraná. 1859-1875. Imagen 447.

[48] Diccionario de la Real Academia Española, edición de 1822. Disponible en www.rae.es.

[49] De acuerdo con la información consignada en los protocolos notariales, es probable que la familia Ferreira-Antunes proviniera de la Villa de San Francisco de Borja, ubicada en Río Grande del Sur. ANPER. Libro del escribano Manuel Calderón 1851-1853. Folio sin numeración.

[50] AGPER. Fondo de Gobierno. Serie VII Estadísticas y Censos 1823-1894. Caja 2. Legajo 7: Estadística de comerciantes.

[51] AGPER. Recopilación de leyes, decretos y acuerdos de Entre Ríos, Tomo I (1821-1824). Copia digital.

[52] AGPER. Fondo de Gobierno. Serie VII Estadísticas y Censos 1823-1894. Caja 1. Legajo 9: Censo de habitantes. Paraná, 1844.

[53] AGPER. Fondo de Gobierno. Serie VII Estadísticas y Censos 1823-1894. Caja 1. Legajo 9: Censo de habitantes. Paraná, 1844.

[54] AGPER. Fondo de Gobierno. Serie VII Estadísticas y Censos 1823-1894. Caja 3. Legajo 1: Censo de habitantes. Paraná, 1849.

[55] AGPER. Fondo de Gobierno. Serie VII Estadísticas y Censos 1823-1894. Caja 3. Legajo 1: Censo de habitantes. Paraná, 1849.

[56] AGPER. Expedientes judiciales (fuera de inventario). Expediente seguido por Salvador Antunes (1868).

[57] AGPER. Expedientes judiciales (fuera de inventario). Expediente seguido por Salvador Antunes (1868).

[58] AGPER. Expedientes judiciales (fuera de inventario). Expediente seguido por Salvador Antunes (1868).

[59] AGPER. Expedientes judiciales (fuera de inventario). Expediente seguido por Salvador Antunes (1868).

[60] AGN. Primer Censo Nacional (1869). Copia digital. Tomo 18. Imagen 275.

[61] AGN. Primer Censo Nacional (1869). Copia digital. Tomo 18. Imagen 275.

[62] AGPER. Expedientes judiciales (fuera de inventario). Expediente seguido por Salvador Antunes (1875).

[63] AGPER. Expedientes judiciales (fuera de inventario). Expediente seguido por Salvador Antunes (1875).

[64] Family Search. Registro de Defunciones de la Parroquia Nuestra Señora del Rosario. Paraná. 1859-1875. Imagen 471.

[65] AGPER. Expedientes judiciales (fuera de inventario). Expediente seguido por Salvador Antunes (1875).

[66] AGPER. Expedientes judiciales (fuera de inventario). Expediente seguido por Salvador Antunes (1875). 
[67] AGPER. Expedientes judiciales (fuera de inventario). Expediente seguido por Joaquín Antunes (1874).

[68] AGN. Segundo Censo Nacional (1895). Copia digital. Paraná, sección 5. Imagen 290.

[69] AGN. Segundo Censo Nacional (1895). Copia digital. Paraná, sección 5. Imagen 290.

[70] AGPER. Expedientes judiciales (fuera de inventario). Testamentaria de Felipe Antunes (1876). 